\title{
A SPECIES DIFFERENCE WITH REGARD TO THE EFFECT OF CORTISONE ACETATE ON BODY WEIGHT, $\gamma$-GLOBULIN AND CIRCULATING ANTITOXIN LEVELS
}

\author{
By JENNIFER SHEWELL* AND D. A. LONG \\ National Institute for Medical Research, Mill Hill, London
}

(With 7 Figures in the Text)

It is generally agreed that the administration of the 11-oxysteroid hormones of the adrenal cortex to the commonly used experimental animals, the rat and the rabbit, produces involution of lymphoid tissue. Since lymphoid tissue is an important site of formation of antibody, several workers have attempted to correlate the effects of adrenal steroids on lymphoid tissue with their effects on immunity. The effect of the 11-oxysteroid adrenal hormones on the immunity of experimental animals, as judged by the amount of circulating antitoxin present in the blood, is not, however, a matter of general agreement. Different workers have obtained widely diverse and conflicting results.

Dougherty and his colleagues reported that an increased agglutinin titre in rabbits, with a rise in the level of circulating $\gamma$-globulin, coincided with maximal dissolution of lymphocytes produced by administration of ACTH or cortisone. These workers also claimed to have extracted a protein indistinguishable from $\gamma$-globulin from lymphocytes (Dougherty, White \& Chase, 1944; White \& Dougherty, 1944; Dougherty, Chase \& White, 1945). Eisen, Mayer, Moore, Tarr \& Stoerk (1947) repeated this work and concluded that corticoids had no such influence on circulating antitoxin. This was the conclusion also of Vollmer \& Samsell (1949), who were unable to modify the response of mice to pneumococcal vaccine with adrenocortical extracts. de Vries (1950) reported that rabbits immunized with crystalline egg albumin had a lowered antibody titre after injection with ACTH. Hayes \& Dougherty (1952) found that adrenal steroids inhibited antibody production in mice, and Bjørnboe, Fischel \& Stoerk (1951), Malkiel \& Hargis (1952) and Buerey, Pierson, de Lavergne \& Burdin (1953) observed the same inhibition in rabbits. On the other hand, Mirick (1951), Havens \& Schaffer (1951) and Eichmann \& Havens (1953) were unable to demonstrate any inhibitory effect of cortisone on the antibody-forming capacity of man. Germuth, Ottinger \& Oyama (1952) found that while cortisone administered in small doses depressed circulating antibody in the rabbit, much larger doses had only slight effects on the circulating antibody of guinea-pigs, while Rosenbaum \& Obinsky (1953) found that cortisone had no effect on antibody levels in the guinea-pig.

* This work forms part of a thesis accepted by the University of London in part fulfilment of the requirements for the degree of Doctor of Philosophy. 
Although some of the work quoted, particularly that claiming to show a rise in titre after adrenocortical stimulation, could be criticized on technical grounds, much of it cannot be subjected to such criticism and this suggests a species difference. It was therefore decided to test the reaction of as many animal species as were available to a very large dose of cortisone acetate, to see whether any basic species difference in response to cortisone existed, which might explain the discrepancies between immunological results. It was known from clinical evidence that man can withstand large, prolonged daily doses of cortisone acetate without losing weight, whereas in our hands prolonged dosage with cortisone invariably decreases the growth rate or produces loss of weight in rats and mice. The aims of the cortisone toxicity experiment were to see if any other species could be found that, like man, was able to maintain body weight under heavy cortisone administration, and also to investigate the effect of cortisone on $\gamma$-globulin and circulating antitoxin levels in different species.

\section{THE EFFECT OF CORTISONE ACETATE ON BODY WEIGHT AND ORGAN WEIGHT}

\section{Method}

In each case the animals tested were young adults. Groups of ten male and ten female animals were weighed daily for 10 days to find their fluctuations in weight. Half the animals, five male and five female, were then injected intramuscularly daily for a further 10 days with cortisone acetate (Merck) $(50 \mathrm{mg}$. $/ \mathrm{kg}$. body weight) suspended in saline, while the controls were injected with saline only. Daily weights were recorded. All animals were killed with chloroform on the eleventh day after starting injections, and complete post-mortem examinations were carried out on all test and control animals. Fresh weights of liver, spleen, thymus, adrenal glands, thyroid glands and sex organs were recorded, and tissue samples were taken for histological examination. Serum samples were taken for electrophoresis. Changes in body weight from the start of the experiment were calculated as percentage change in weight from the weight on the first day of injections, and organ weights at post-mortem were expressed as mg. fresh tissue per $100 \mathrm{~g}$. final body weight. Differences in mean organ weight between control and treated groups were analysed for significance using 'Student's' $t$ test. The standard deviation from the mean organ weight of each group is represented on the charts.

The animal species tested, and their approximate initial weights, were: Parkes's strain of albino mice $(25 \mathrm{~g}$.), hooded rats $(175 \mathrm{~g}$.$) , the Hampstead strain of$ albino guinea-pigs $(500 \mathrm{~g}$.$) , Himalayan rabbits ( 1500 \mathrm{~g}$.$) , albino ferrets (500 \mathrm{~g}$. and Rhesus monkeys (3000 g.). In the case of the monkeys, only ten animals were used, the test and control groups each consisting of four males and one female.

The rabbits and guinea-pigs were fed upon Bruce \& Parkes's (1947) pelleted diet 18, supplemented with hay. The rats, mice and monkeys were fed on Bruce \& Parkes's (1949) pelleted diet 41. The ferrets were given diet 41 mixed with equal parts by weight of 'Lassie' proprietary dog food, which is rich in protein, and milk 
to drink. Since the monkey and the guinea-pig are unable to synthesize ascorbic acid, they were also given cabbage daily. With the exception of the ferrets all animals had water to drink.

\section{Results}

Of all the species tested, only the monkeys and guinea-pigs maintained their weight under treatment with cortisone acetate. From the graphs (Figs. 1, 2), it can be seen that the mice and rats lost weight rapidly. The initial loss of weight

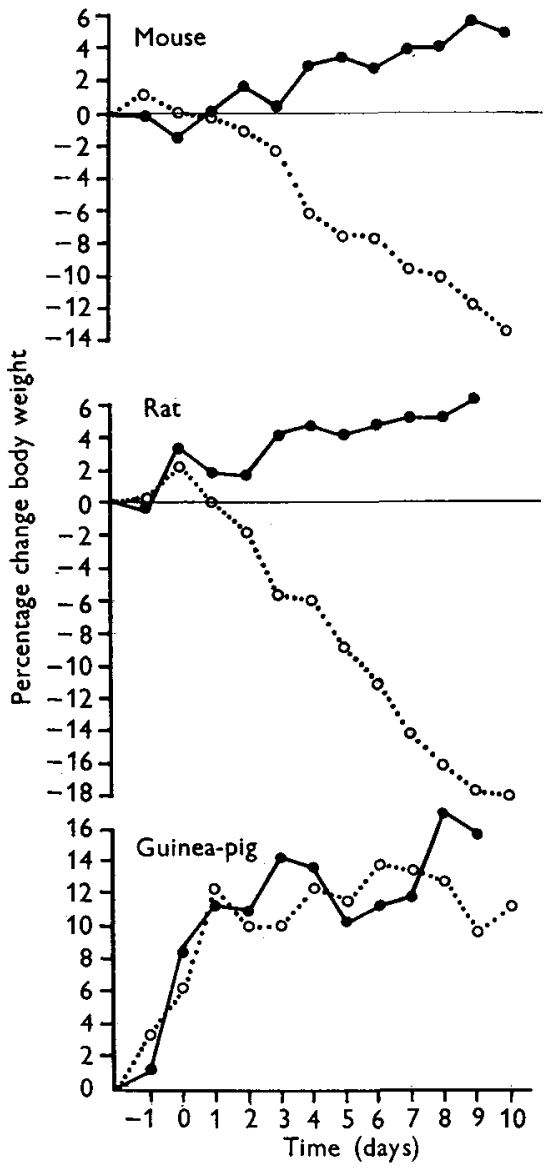

Fig. 1

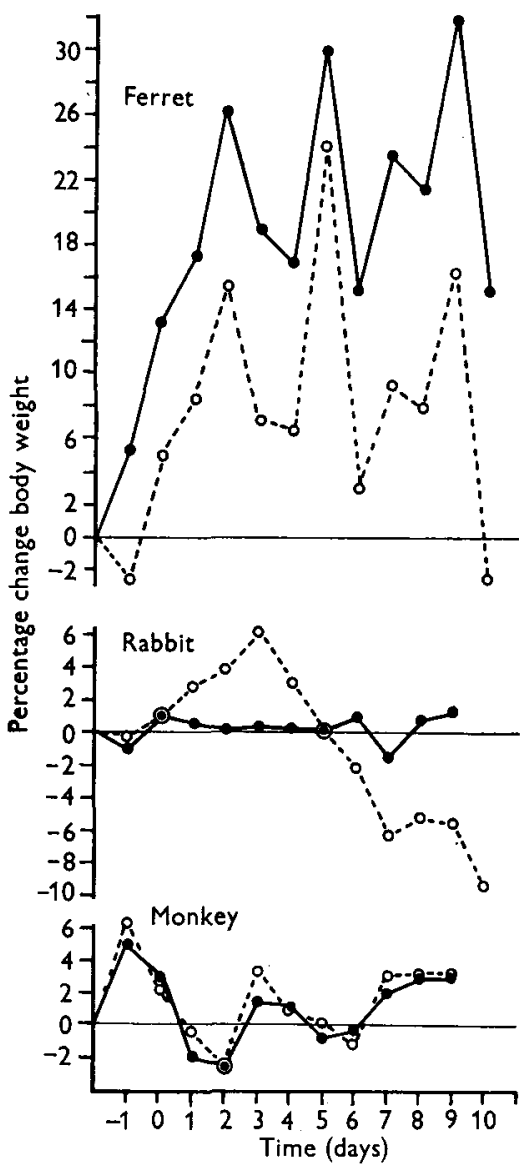

Fig. 2

Figs. 1 and 2. The effect of cortisone acetate $(50 \mathrm{mg} . / \mathrm{kg}$.) on body weight in different species. The continuous line represents controls, the broken line treated animals.

of the rabbits was masked by a 3-4-day period of fluid retention, but once this oedema had disappeared they lost weight progressively. The weight charts for the ferrets show a loss of weight under cortisone administration but are irregular, since this animal is not a continuous feeder as are all other species tested except the monkey.

The guinea-pigs and monkeys maintained both weight and condition throughout the 10-day test period. Since these two species were both receiving cabbage daily, 
a theoretical possibility existed that their resistance to cortisone (i.e. their ability to maintain weight under prolonged and heavy cortisone administration) might be due to the cabbage. A second group of rats was therefore treated with $50 \mathrm{mg} . / \mathrm{kg}$. body-weight cortisone acetate and given cabbage extra to their accustomed diet. Although the rats ate the cabbage they still lost weight.

The outstanding difference between the animals termed 'cortisone-resistant', the monkey and the guinea-pig, that maintained their weight under heavy cortisone treatment, and those termed 'cortisone-sensitive', the rat, mouse, rabbit and ferret, that rapidly lost weight and condition, was the marked wasting of muscle in the latter group. This muscle wasting does not indicate a mere side-

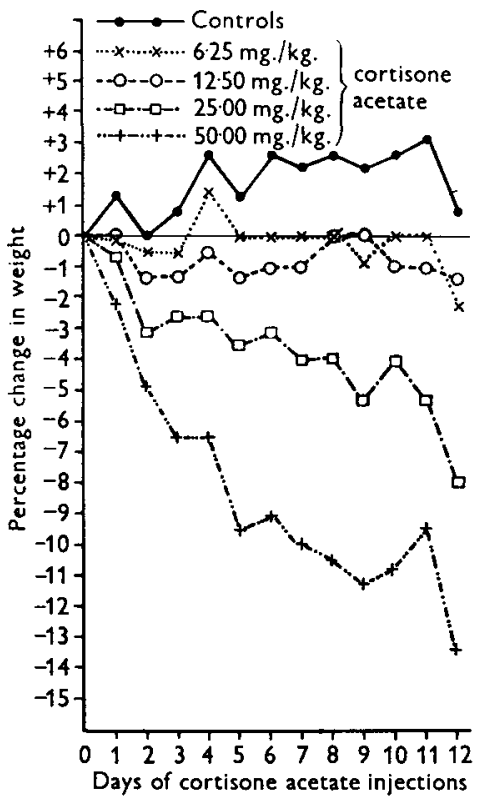

Fig. 3

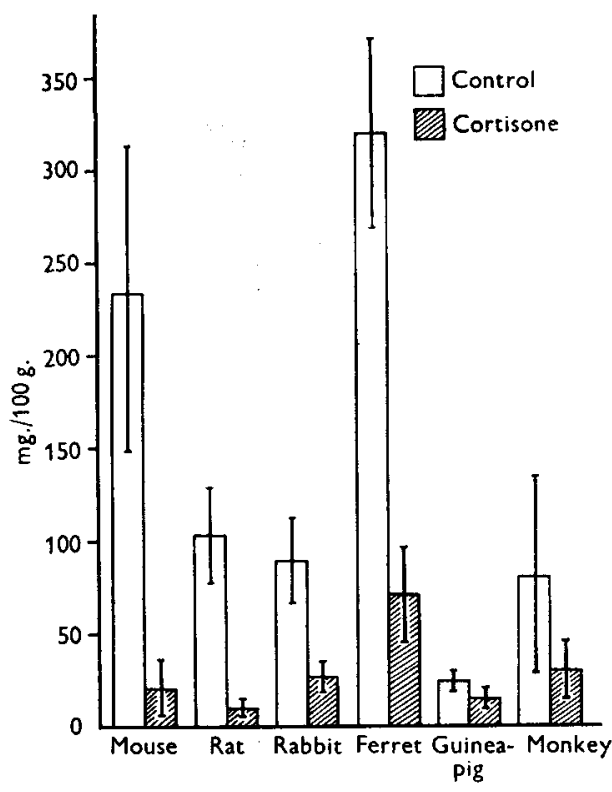

Fig. 4

Fig. 3. Body-weight dose response of female rats treated with cortisone acetate.

Fig. 4. The effect of cortisone acetate $(50 \mathrm{mg} . / \mathrm{kg}$.) on the thymus weight of different species. The standard deviation from the mean is represented on each block.

effect resulting from gross cortisone toxicity, for cortisone-sensitive animals, such as the rat, lose weight on doses of cortisone acetate much smaller than that employed in this series of experiments. Both male and female rats treated with doses of cortisone acetate ranging from 6.25 to $50 \mathrm{mg}$. $/ \mathrm{kg}$. showed a loss of weight roughly proportional to the dose given (Fig. 3). The remarkable thing is that the monkey and guinea-pig should not undergo this muscle wasting even when a dose of $50 \mathrm{mg} . / \mathrm{kg}$. is given.

\section{Thymus and spleen}

\section{Post-mortem findings}

The administration of cortisone induces atrophy of lymphoid tissue (Ingle, 1938; Wells \& Kendall, 1940). The lymphoid tissue of the thymus is particularly susceptible to this effect (Selye, 1950; Weaver, 1955). Thymus involution produced 
by cortisone is apparently due to actual cell damage. Udall (1955) found no evidence for a decrease in the number of mitotic divisions in the thymus, but suggested that, in addition to damaging the thymocytes, cortisone prevented the maturation of their precursors. The greatest degree of thymic atrophy was shown by those animals whose body weight decreased-the mouse, the rat, rabbit and ferret (Fig. 4). The mean thymus weight of the cortisone-treated guinea-pigs was significantly smaller than that of the controls $(p<0 \cdot 01)$, although even with this extremely sensitive tissue, the thymus, the effect in a resistant species was not nearly as marked as with the cortisone-sensitive animals. The effect of cortisone acetate on the thymus of the monkey was not significant $(p>0 \cdot 05)$. Thymus atrophy in all cases was due to a decrease in lymphoid tissue.

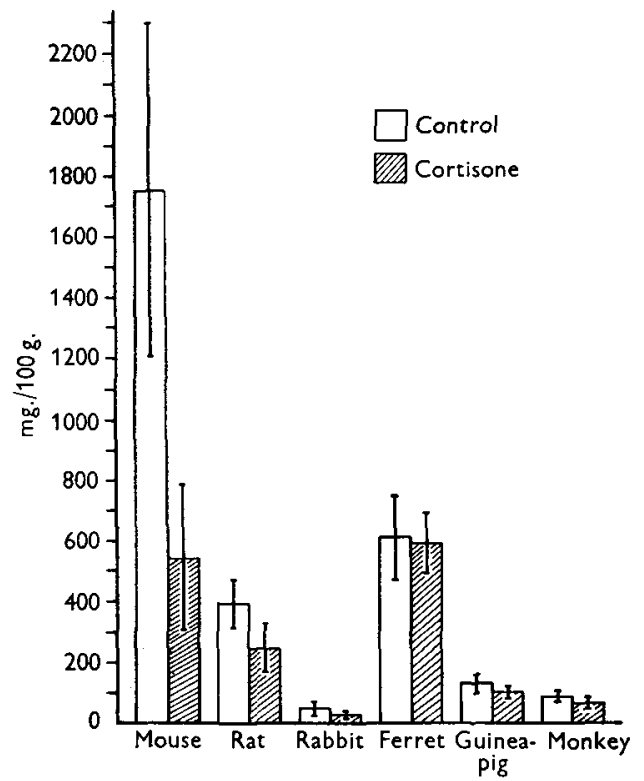

Fig. 5

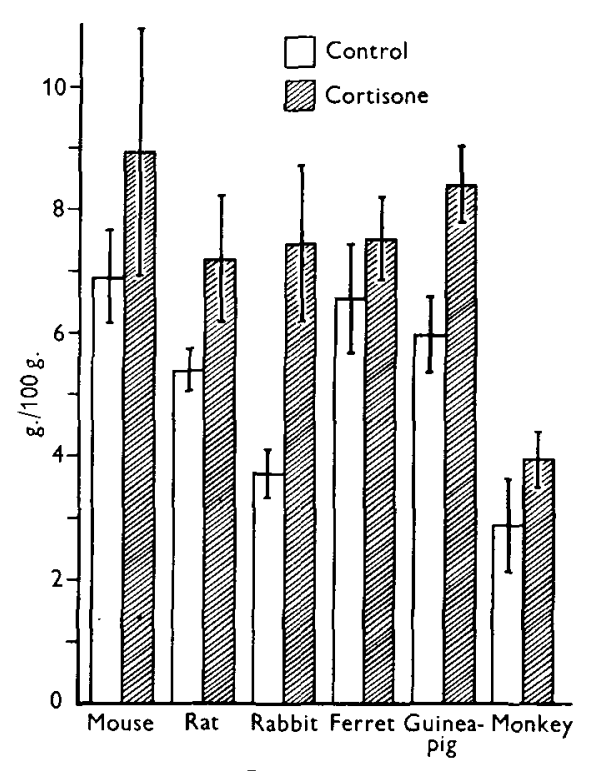

Fig. 6

Fig. 5. The effect of cortisone acetate $(50 \mathrm{mg} . / \mathrm{kg}$.) on the spleen weight of different species.

Fig. 6. The effect of cortisone acetate $(50 \mathrm{mg} . / \mathrm{kg}$.) on the liver weight of different species. The standard deviation from the mean is represented on each block.

The difference in sensitivity to cortisone of the two groups of animals is also shown when the spleen weight is taken as a measure of lymphoid involution. Spleen weight is not as reliable an index of lymphoid tissue as thymus weight, since the amount of lymphoid tissue in the spleen is comparatively small, and since the spleen is a blood depôt there is greater individual variation in weights at post-mortem examination.

The significant decrease in spleen weight shown by the rat and mouse indicates the marked sensitivity to cortisone of the lymphatic tissue of these species (Fig. 5). There was no significant decrease in the weight of the spleens of either the cortisonetreated monkey or guinea-pig, nor could any microscopic alteration in these organs be detected. 
Liver

The ratio of liver weight to body weight increased in all species (Fig. 6). Since the rat, mouse, rabbit and ferret all lost weight on cortisone treatment, it is difficult to decide whether the relative increase in liver weight represented a true liver hypertrophy resulting from an increase in the size of the liver cells, or an apparent hypertrophy due to the liver size remaining constant in a shrinking carcass. In the case of the monkey and guinea-pig, loss of body weight did not occur, and the histological picture of these livers is compatible with a functional hypertrophy; the hepatic cells increased in size, with a resulting compression of the sinusoids. The cells contained glycogen, demonstrated with Schiff's stain.

\section{Adrenal glands}

A marked decrease in weight of the adrenal glands was observed in all cortisonetreated animals. This is the typical response 'disuse atrophy', obtained from any endocrine organ when exogenous hormones of that organ are administered to the intact animal over a prolonged period.

No difference between control and treated groups was observed with regard to the weights of the sex organs or the thyroid gland.

From this study of body-weight and organ-weight changes, it is apparent that, of the commonly used experimental animals, only the guinea-pig and Rhesus monkey resemble man in being able to maintain their weight under heavy cortisone dosage.

\section{THE EFFECT OF CORTISONE ACETATE ON $\gamma$-GLOBULIN LEVELS IN CIRCULATING BLOOD}

Electrophoretic analyses were carried out on a Tiselius apparatus.

Serum was taken for electrophoretic analysis after cortisone toxicity experiments on guinea-pigs, monkeys and rabbits. The species difference in response to cortisone administration was confirmed by the electrophoretic analyses obtained. The $\gamma$-globulin peaks of the cortisone-treated guinea-pig and monkey were indistinguishable from those in the sera of the control, untreated animals. The electrophoretic picture taken from the sera of rabbits given $50 \mathrm{mg} . / \mathrm{kg}$. body-weight cortisone was poor, since there was gross interference due to the high degree of lipaemia shown by the treated rabbits. In an attempt to overcome this difficulty a second series of Himalayan rabbits was treated with $25 \mathrm{mg}$./kg. body-weight cortisone, which produced a less lipaemic serum. The sera from the cortisonetreated rabbits on electrophoretic analysis showed a complete suppression of the $\gamma$-globulin peak (Fig. 7).

The species difference in response to cortisone with regard to loss or maintenance of body weight can therefore be demonstrated with regard to $\gamma$-globulin synthesis also. Cortisone-resistant animals, that maintain their body weight under heavy cortisone administration, show no suppression of $\gamma$-globulin formation, while heavy cortisone administration produces, in a cortisone-sensitive animal, complete suppression of $\gamma$-globulin synthesis, as judged from electrophoretic analyses. 
(a)

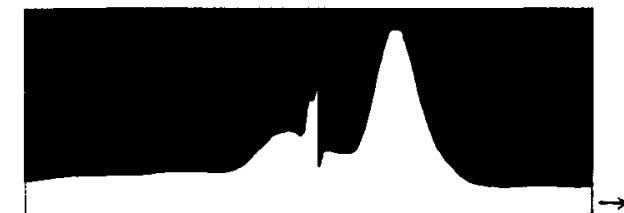

(b)

(d)

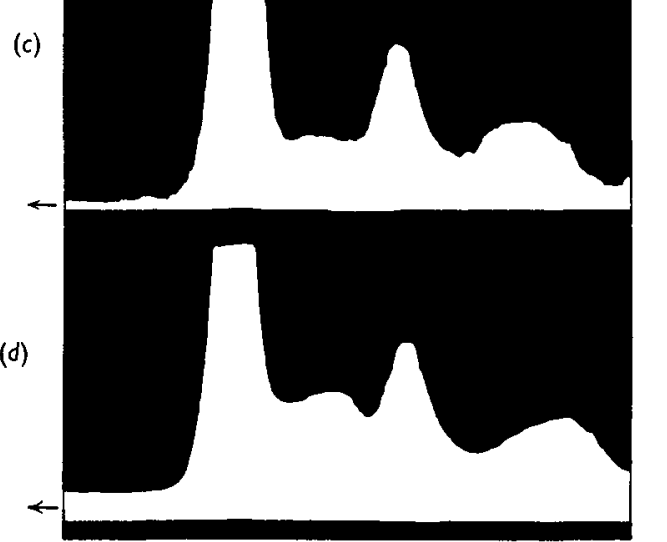

Fig. 7. Electrophoretic pictures of rabbit and monkey serum. (a) Rabbit serum-cortisone acetate $25 \mathrm{mg}$. $/ \mathrm{kg}$. The $\gamma$-globulin peak is suppressed. (b) Rabbit serum-control. Normal $\gamma$-globulin peak. (c) Monkey serum - cortisone acetate $50 \mathrm{mg} . / \mathrm{kg}$. Normal $\gamma$-globulin peak. (d) Monkey serum-control. Normal $\gamma$-globulin peak. Interference in $(a)$ is due to lipaemia.

\section{THE EFFECT OF CORTISONE ACETATE ON CIRCULATING ANTITOXIN LEVELS}

\section{Method}

In the course of the cortisone toxicity experiments, both the rabbits and the Rhesus monkeys were immunized with diphtheria toxoid. The effect of cortisone acetate on the secondary response was studied, since the secondary response is of greater magnitude than the primary, and it is easier to measure differences between two larger than between two smaller responses. In both cases, the first dose of antigen was given 28 days before the second dose, which was given simultaneously with the first of the ten cortisone injections.

The Rhesus monkeys were given $10 \mathrm{Lf}$ of an alum-precipitated diphtheria toxoid (Ba536) in $2 \mathrm{ml}$. normal saline intramuscularly into the right hind leg, while the rabbits received $5 \mathrm{Lf}$ in $1.0 \mathrm{ml}$. saline. (Cortisone acetate injections were 
given into the left hind leg.) All the animals were bled from the heart under chloroform anaesthesia just before death, and individual and pooled antitoxin estimations carried out on the serum samples from each group.

\section{Results}

The mean values of antitoxin for the monkeys were the same, $14 \cdot 0 \mathrm{i} . \mathrm{u} / \mathrm{ml}$. , for both the control and cortisone-treated groups. The range of antitoxin titres in each group was $10 \cdot 0-25 \cdot 0 \mathrm{i} . \mathrm{u} . / \mathrm{ml}$. for the control group, and $10 \cdot 0-20 \cdot 0 \mathrm{i} . \mathrm{u} . / \mathrm{ml}$. for the cortisone-treated group. No difference between pooled samples of these groups could be detected using the indirect neutralization method (Miles, 1949) or the Römer \& Sames technique (1909). No difference between the immunity of the two groups of monkeys could be detected by a multiple Schick test.

On the other hand, the cortisone-treated rabbits all had less than $1.0 \mathrm{i} . \mathrm{u} . / \mathrm{ml}$. (mean $0.75 \mathrm{i} . \mathrm{u} . / \mathrm{ml}$.), whereas the control rabbits all had more than $7.5 \mathrm{i} . \mathrm{u} . / \mathrm{ml}$. (mean $12 \cdot 8$ i.u./ml.).

\section{CONCLUSIONS}

On the basis of these experimental findings, a distinction is made between two groups of animal species: on the one hand, those termed cortisone-sensitive, that are unable to maintain their body weight under prolonged heavy cortisone administration, whose $\gamma$-globulin synthesis is depressed and whose capacity to form antitoxin markedly suppressed, and on the other, those species termed cortisone-resistant, that do not lose weight under heavy cortisone dosage, and whose $\gamma$-globulin synthesis and antibody-forming capacity are unimpaired by cortisone. Rats, mice, rabbits and ferrets are all cortisone-sensitive, while the only experimental animals so far found to resemble man in his resistance to cortisone are the Rhesus monkey and the guinea-pig. It is felt that the confusion in the literature regarding the effect of the hormones of the adrenal cortex on circulating antibody, and the discrepancies observed between laboratory and clinical evidence, would both be resolved if this broad species difference were appreciated.

We are indebted to Mrs A. Dovey, B.Sc., for the electrophoretic analyses; to Miss M. V. Mussett, B.Sc., for statistical analyses; and to Dr Janet S. F. Niven for the histology and advice on its interpretation.

We are grateful to Miss S. McBride for expert technical assistance.

\section{REFERENCES}

BJørnboe, M., Fischel, E. E. \& Stoerk, H. C. (1951). J. exp. Med. 93, 37.

Bruce, H. M. \& Parkes, A. S. (1947). J. Hyg., Camb., 45, 70.

Bruce, H. M. \& Parkes, A. S. (1949). J. Hyg., Camb., 47, 202.

Bufrey, J., Pierson, M., de Lavergne, E. \& Burdin, J. C. (1953). C.R. Soc. Biol., Paris, $147,849$.

DE VRIES, J. A. (1950). J. Immunol. 65, 1.

Dougherty, T. F., Chase, J. H. \& White, A. (1945). Proc. Soc. exp. Biol., N.Y., 58, 135.

Dougherty, T. F., White, A. \& Chase, J. H. (1944). Proc. Soc. exp. Biol., N.Y., 56, 28.

Eichmann, P. L. \& Havens, W. P. (1953). J. clin. Endocrin. 13, 648.

Eisen, H. J., Mayer, M. M., Moore, D. H., TarR, R.-R. \& Stoerk, H. C. (1947). Proc. Soc. exp. Biol., N.Y., 65, 301. 
Germuth, F. G., Ottinger, B. \& Oyama, J. (1952). Proc. Soc. exp. Biol., N.Y., 80, 188. Havens, W. P. \& Schaffer, J. M. (1951). Fed. Proc. 10, 410.

HaYes, S. P. \& DougherTy, T. F. (1952). Fed. Proc. 11, 67.

INGLe, D. J. (1938). Proc. Soc. exp. Biol., N.Y., 38, 443.

Markiel, S. \& Hargis, B. J. (1952). J. Immunol. 69, 217.

Mrues, A. A. (1949). Brit. J. exp. Path. 30, 319.

MiricK, G. S. (1951). Johns Hopk. Hosp. Bull. 88, 332.

Römer, P. H. \& SAMES, Th. (1909). Z. ImmunForsch. 3, 344.

Rosenbaum, P. \& Obinsky, W. (1953). Proc. Soc. exp. Biol., N.Y., 83, 502.

SkLYe, H. (1950). Stress, p. 452. Montreal, Canada: Acta Inc.

UDALL, V. (1955). J. Path. Bact. 69, 11.

Vollmer, E. P. \& SAMSELl, J. E. (1949). Endocrinology, 45, 204.

Weaver, J. A. (1955). J. Path. Bact. 69, 133.

Wells, B. B. \& Kendall, E. C. (1940). Proc. Mayo Clin. 15, 133, 324.

White, A. \& Dougherty, T. F. (1944). Proc. Soc. exp. Biol., N.Y., 56, 26.

(MS. received for publication 23. IV. 56) 